\title{
Positive response to neoadjuvant
} cyclophosphamide and doxorubicin in topoisomerase II nonamplified/HER2/neu negative/polysomy 17 absent breast cancer patients

This article was published in the following Dove Press journal:

Cancer Management and Research

19 August 2010

Number of times this article has been viewed

\author{
Henry G Kaplan' \\ Judith A Malmgren 2,3 \\ Mary Atwood' \\ Lynn C Goldstein ${ }^{4}$ \\ 'Swedish Cancer Institute at \\ Swedish Medical Center, Seattle, \\ Washington, USA; ${ }^{2} \mathrm{HealthStat}$ \\ Consulting Inc., Seattle, Washington, \\ USA; ${ }^{3}$ School of Public Health and \\ Community Medicine, Department \\ of Epidemiology, University of \\ Washington, Seattle, Washington, USA; \\ ${ }^{4}$ PhenoPath Laboratories, Seattle, \\ Washington, USA
}

Purpose: Human epidermal growth factor receptor 2 (HER2)/neu, topoisomerase II alpha (TOP2A), and polysomy 17 may predict tumor responsiveness to doxorubicin (DOX) therapy.

Methods: We identified neoadjuvant DOX/cyclophosphamide treated breast cancer patients in our registry from 1997 to 2008 with sufficient tissue for testing $(n=34)$. Fluorescence in situ hybridization (FISH) testing was done on deparaffinized tissue sections pretreated using vendor's standard protocol modification, and incubated with US Food and Drug Administration approved Abbott Diagnostics Vysis PathVysion ${ }^{\mathrm{TM}}$ probe set, including Spectrum-Green-conjugated probe to $\alpha$-satellite DNA located at the centromere of chromosome 17 (17p11.1-q11.1) and a Spectrum-Orange-conjugated probe to the TOP2A gene. Morphometric analysis was performed using a MetaSystems image analysis system. Manual counting was performed on all samples in which autofluorescence and/or artifact prevented the counting of sufficient numbers of cells. A ratio $>2.0$ was considered positive for TOP2A amplification. Polysomy 17 (PS17) presence was defined as signals of $\geq 2.5$. Outcomes were pathological complete response (pCR), partial response (PR), and nonresponse (NR).

Results: Of 34 patients tested, one was TOP2A amplified (hormone receptor negative/HER2 negative, partial responder). The subset of TOP2A nonamplified, HER2 negative, and PS17 absent $(\mathrm{n}=23)$ patients had treatment response: $\mathrm{pCR}=2(9 \%), \mathrm{PR}=14(61 \%)$, and $\mathrm{NR}=7$ (30\%). Including the two PS17 present and HER2-positive patients $(n=33), 76 \%$ of TOP2A nonamplified patients had $\mathrm{pCR}$ or PR.

Conclusions: We observed substantial treatment response in patients lacking three postulated predictors that would be difficult to attribute to cyclophosphamide alone. Patients who are HER2 negative and lack TOP2A amplification and PS17 should not be excluded from receiving DOX-containing regimens.

Keywords: neoadjuvant chemotherapy, response rates, anthracycline therapy

\section{Introduction}

Recent reports have proposed topoisomerase II alpha (TOP2A) biomarker status as a potential predictor of tumor responsiveness to doxorubicin (DOX) therapy. ${ }^{1}$ These studies predominantly evaluated relapse-free survival in the adjuvant setting related to human epidermal growth factor receptor 2 (HER2)-neu and TOP2A status although more recent studies have evaluated direct response rates in the neoadjuvant setting. ${ }^{1-6}$
Correspondence: Henry G Kaplan Swedish Medical Center, Swedish Cancer Institute, I22I Madison St, Seattle, WA 98104, USA

Tel + I 206-386-2828

Fax + I 206-386-2729

Email hank.kaplan@swedish.org 
Contradictory results have been reported for anthracycline response among HER2 amplified tumors, although in general anthracycline responsiveness has been correlated with HER2 positivity. ${ }^{7,8}$ Konecny et al ${ }^{1}$ have correlated anthracycline responsiveness with TOP2A amplification and deletion, though again there is no unanimity regarding this observation. Paradoxically, favorable response to anthracyline therapy, especially in the neoadjuvant setting, has been observed in patients with triple-negative breast cancer. $^{9}$

The TOP2A gene product is a target of anthracyclines, and the gene is located in chromosome 17 (17q21-22) in close proximity to HER2. Polysomy 17 (PS17) has also been proposed as a predictive marker for anthracycline sensitivity although there is far less data available regarding this observation. ${ }^{8}$ Our study aim is to evaluate tumor response in a retrospective cohort of breast cancer patients treated with neoadjuvant DOX and cyclophosphamide (C) in relation to HER2, topoisomerase II, and PS17 expression.

\section{Materials and methods}

We retrospectively identified all breast cancer patients in our community-based cancer clinic registry cohort treated with neoadjuvant DOX and cyclophosphamide (C) only prior to surgery. Hormone receptor (HR) and HER2 testing were completed as part of their initial clinical evaluation. Forty-five patients in our patient registry had neoadjuvant $\mathrm{DOX} / \mathrm{C}$ treatment and were given no other neoadjuvant therapy. Thirty-four of these patients had sufficient tissue available for testing and adequate signal for measurement of TOP2A gene amplification. Choice of neoadjuvant treatment drug and number of cycles to be delivered was made by the treating physician.

Estrogen receptor and progesterone receptor status were assessed by immunohistochemistry (IHC) at various local laboratories; HER2 status was assessed by either IHC or fluorescent in situ hybridization (FISH) or both in the case of an equivocal IHC result (FISH). Breast biopsy tissue was preserved in paraffin blocks and stored at room temperature prior to testing. FISH testing was done on deparaffinized tissue sections pretreated using a modification of the vendor's standard protocol, and then incubated with the US Food and Drug Administration-approved Vysis PathVysion ${ }^{\mathrm{TM}}$ probe set, which includes Spectrum-Green-conjugated probe to the $\alpha$-satellite DNA located at the centromere of chromosome 17 (17p11.1-q11.1) and a Spectrum-Orange-conjugated probe to the TOP2A gene (Abbott Diagnostics, Chicago, IL, USA).
For every batch of tumor sections, appropriate quality control sections were used for FISH testing. Morphometric analysis was performed using a MetaSystems image analysis system, incorporating the Metafer software with extended focus/ tile sampling methodology (MetaSystems, Altlussheim, Germany). Manual counting was performed on all samples in which autofluorescence and/or artifact prevented the counting of sufficient numbers of cells. A ratio $>2.0$ is considered positive for TOP2A amplification. PS17 presence was defined as signal of $\geq 2.5$. Figure 1 illustrates TOP2A present amplification.

Pretreatment tumor size was determined by imaging and physical examination and posttreatment size was determined from the pathological specimen and the pathologist's report with response measured postsurgery after receipt of DOX/C neoadjuvant therapy. The clinical end point was response to treatment and was measured as pathological complete response (pCR), partial response (PR), and nonresponse (NR) using RECIST criteria. ${ }^{10}$ Response was assigned after surgery and pCR was assigned if there was no residual disease in the breast tissue or lymph nodes. PR was assigned if there was evidence of $30 \%$ or greater decrease in tumor size (PR) and no response (NR) if the tumor size reduction was less than $30 \%$.

Statistical analysis was done using SPSS 17.0 software for univariate and bivariate analysis. ${ }^{11}$ Pearson chi-square tests were done to identify significant differences between groups using a 2-sided test for probability using the Fisher's Exact test for small number comparisons.

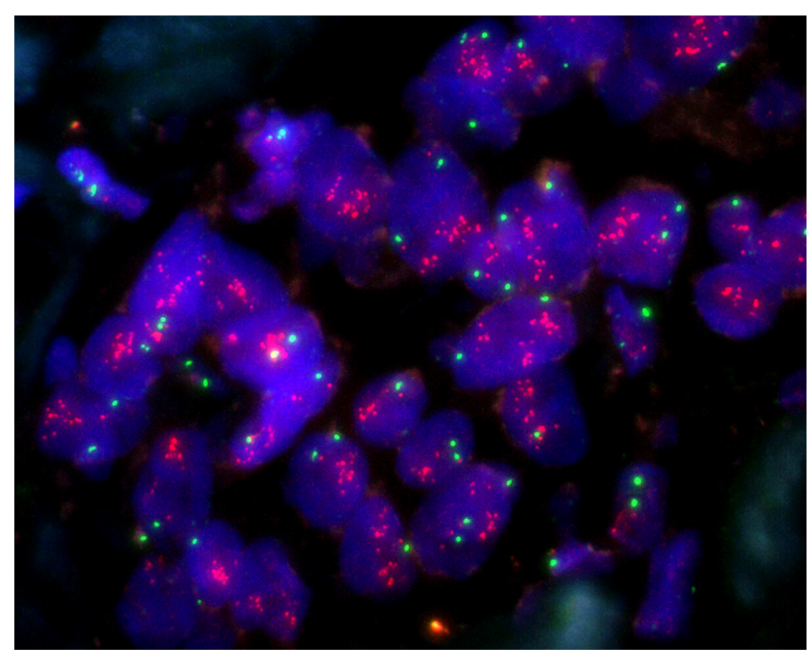

Figure I TOP2A amplified cells. 


\section{Results}

The 34 patients tested for TOP2A were diagnosed between 1997 and 2008 with TNM stage II-IV breast cancer and were treated with neoadjuvant DOX and cyclophosphamide. Patients' age range was $29-66$ years with a mean of 46.47 and a median age of 46 . Seventy-six percent of the patients had clinically positive lymph node status. Clinical tumor size at the time of diagnosis was 1.6-11.0 cm with 5/34 (14.7\%) equal to $1.6-2.5 \mathrm{~cm}$, a mean of 6.13 $\mathrm{cm}$ and median of $6.0 \mathrm{~cm}$. The most common histologic type was ductal carcinoma (79\%) with $88 \%$ exhibiting high histologic grade and $71 \%$ with high nuclear grade. Out of 34 patients tested for topoisomerase II, one was TOP2A amplified (HR-/HER2-, partial responder). A total of 18 out of 34 were HR+ and 9 were HER2+. Data are presented in Table 1.

Twenty-four of the 34 patients were treated with 4 cycles of DOX/C, 3 of 34 had 5 cycles of DOX/C, and 4 of 34 had 6 cycles of DOX/C. One of 34 patients had 2 cycles and 1/34 had 3 cycles. One of the 34 patients had a weekly treatment protocol as part of a randomized clinical trial (RCT) receiving 15 weeks of DOX/C therapy. The 2 patients with less than 4 cycles of therapy had early substantial reduction in tumor size (PR) and went to surgery. Descriptives are presented in Table 1.

Among the subset of TOP2A normal patients $(\mathrm{n}=33)$, treatment response was $\mathrm{pCR}=4(12.1 \%), \mathrm{PR}=21(63.6 \%)$, and NR $=8(24.2 \%)$ with the majority $(75.7 \%)$ exhibiting significant responsiveness ( $\mathrm{pCR}$ or PR) to DOX/C. Distribution by HR and HER2 status and therapy response for the subset of TOP2A nonamplified/PS17 absent patients $(\mathrm{n}=31)$ was (1) HR-/HER2- $(\mathrm{n}=9), 22 \% \mathrm{pCR}, 56 \% \mathrm{PR}, 22 \% \mathrm{NR}$; (2) HR+/HER2- $(\mathrm{n}=14), 64 \%$ PR, 36\% NR; (3) HR-/ HER $2+(\mathrm{n}=6), 33 \% \mathrm{pCR}, 67 \% \mathrm{PR}$; and (4) HR+/HER 2+ $(\mathrm{n}=2), 50 \%$ PR, $50 \%$ NR. For the subset of HER2 negative and TOP2A nonamplified patients $(\mathrm{n}=24)$, the response rates were $8 \%$ pCR $(2 / 24), 63 \%$ PR $(15 / 24)$, and $29 \%$ NR (7/24). For the subset of HER2 negative, TOP2A nonamplified and PS17 absent patients $(n=23)$, treatment response were $\mathrm{pCR}=2(9 \%), \mathrm{PR}=14(61 \%)$, and $\mathrm{NR}=7(30 \%)$. See Table 2 and Figure 2 for summary.

When response to treatment was analyzed for all cases $(\mathrm{n}=34)$ by HR and HER 2 status, the best response was among the HR-/HER2+ patients with $100 \%$ partial or complete response followed by the triple-negative group with $80 \%$ partial or complete response (Pearson $\chi^{2}=7.32,6$ degrees of freedom, $P=0.293$; Table 3 ).
Table I Descriptors of patients tested for TOP2A $(n=34)$

\begin{tabular}{|c|c|}
\hline Variable & $\mathbf{N}(\%)$ \\
\hline \multicolumn{2}{|l|}{ Age in years } \\
\hline Range & $29-66$ \\
\hline Mean & 46.47 \\
\hline \multicolumn{2}{|l|}{ TNM stage } \\
\hline II & II (32\%) \\
\hline III & $19(56 \%)$ \\
\hline IV & $4(12 \%)$ \\
\hline \multicolumn{2}{|l|}{ Lymph node status } \\
\hline Negative & $8(24 \%)$ \\
\hline Positive & $26(76 \%)$ \\
\hline \multicolumn{2}{|l|}{ Clinical tumor size, $\mathrm{cm}$} \\
\hline Range & $1.6-11.0$ \\
\hline Mean & 6.13 \\
\hline \multicolumn{2}{|l|}{ Histologic type } \\
\hline Ductal & $27(79 \%)$ \\
\hline Lobular & $3(9 \%)$ \\
\hline Other & $4(12 \%)$ \\
\hline \multicolumn{2}{|l|}{ Histologic grade } \\
\hline Intermediate & $2(9 \%)$ \\
\hline High & $30(88 \%)$ \\
\hline \multicolumn{2}{|l|}{ Nuclear grade } \\
\hline Low to intermediate & $9(26 \%)$ \\
\hline Intermediate & I (3\%) \\
\hline High & $24(7 \mid \%)$ \\
\hline $\mathrm{ER}=$ positive & $17(50 \%)$ \\
\hline $\mathrm{PR}=$ positive & II (32\%) \\
\hline Her2 = positive & $9(27 \%)$ \\
\hline \multicolumn{2}{|l|}{ TOP2A } \\
\hline Normal & $33(97 \%)$ \\
\hline Amplified & I (3\%) \\
\hline \multicolumn{2}{|l|}{ PSI7 } \\
\hline Not present & 32 (94\%) \\
\hline Present & $2(6 \%)$ \\
\hline \multicolumn{2}{|c|}{ Number of treatment cycles } \\
\hline Weekly & I (3\%) \\
\hline$<4$ & $2(6 \%)$ \\
\hline 4 & $24(7 \mid \%)$ \\
\hline 5 & $3(9 \%)$ \\
\hline 6 & $4(12 \%)$ \\
\hline
\end{tabular}

Abbreviations: ER, estrogen receptor; PR, progesterone receptor; HER2, human epidermal growth factor receptor 2; TOP2A, topoisomerase II alpha; PSI7, polysomy 17.

Table 2 Summary of response to treatment by HER2 negative, TOP2A absent, and polysomy 17 absent status

\begin{tabular}{lllllll}
\hline $\begin{array}{l}\text { HER2 } \\
\text { status }\end{array}$ & $\begin{array}{l}\text { TOP2A } \\
\text { status }\end{array}$ & $\begin{array}{l}\text { Polysomy 17 } \\
\text { status }\end{array}$ & N & PCR, \% & PR, \% & NR, \% \\
\hline- & Nonamplified & - & 33 & 12 & 64 & 24 \\
- & Nonamplified & Absent & 31 & 13 & 61 & 26 \\
Negative & Nonamplified & - & 24 & 8 & 63 & 29 \\
Negative & Nonamplified & Absent & 23 & 9 & 61 & 30 \\
\hline
\end{tabular}

Abbreviations: HER2, human epidermal growth factor receptor 2; TOP2A, topoisomerase II alpha, PCR, pathological complete response; PR, partial response; NR, nonresponse. 


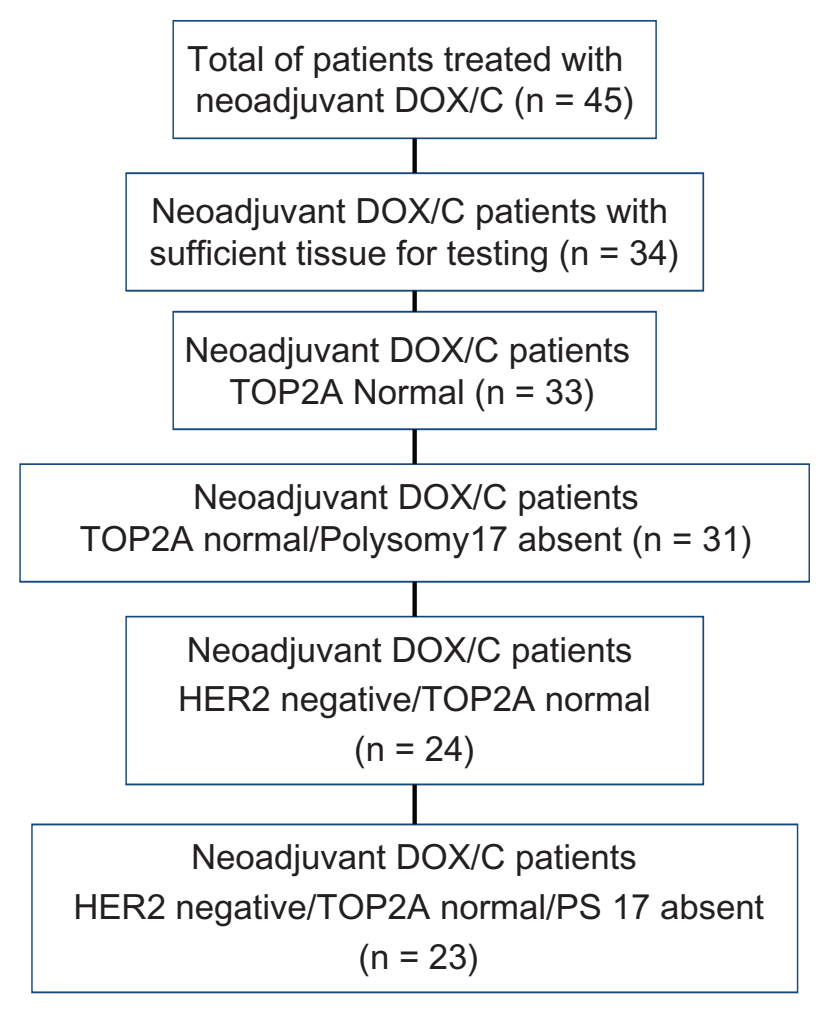

Figure 2 Diagram of neoadjuvant treatment study subjects.

\section{Discussion}

Topoisomerase is a known target for anthracycline cytotoxicity and it has been proposed that alterations in TOP2A correlate with clinical antitumor activity making TOP2A a biomarker candidate for treatment selection decision making. This theory has been evaluated by retrospective review of TOP2A status and mortality outcomes of patients in randomized controlled trials (RCTs) and cohort studies, and response to treatment in neoadjuvant studies with mixed results in all three types of studies. ${ }^{5,9,10,12-14}$ Similarly, HER2 status has been correlated with anthracycline response to varying degrees, though reviews of the literature have led some investigators to conclude that anthracycline benefit may not be predicted

Table 3 Response to treatment by hormone receptor and HER2 status $(n=34)^{a}$

\begin{tabular}{llllll}
\hline $\begin{array}{l}\text { Hormone receptor } \\
\text { status }\end{array}$ & $\begin{array}{l}\text { HER2 } \\
\text { status }\end{array}$ & N & pCR, \% & PR, \% & NR, \% \\
\hline Negative & Negative & 10 & 20 & 60 & 20 \\
Positive & Negative & 15 & 0 & 67 & 33 \\
Negative & Positive & 6 & 33 & 67 & 0 \\
Positive & Positive & 3 & 0 & 67 & 33 \\
Total & & 34 & 12 & 65 & 24 \\
\hline
\end{tabular}

aPearson $\chi^{2}=7.32,6$ degrees of freedom, $P=0.293$ (3 zero cells).

Abbreviations: HER2, human epidermal growth factor receptor 2; $P C R$, pathological complete response; PR, partial response; NR, nonresponse. by HER 2 or TOP2A status. ${ }^{15,16}$ Most recently, Bartlett et al ${ }^{8}$ proposed that PS17 duplication (CH17CEP) is the strongest predictor of treatment benefit with anthracyclines. ${ }^{8}$ They observe that the presence of HER2/TOP2A on chromosome 17 may explain the inconsistent results observed in regards to these biomarkers and anthracycline benefit.

To further assess these indicators, we reviewed the response of all patients who received neoadjuvant DOX/C alone at our institution. In particular, we examined the response of the patients in this group who lacked all three putative predictors of anthracycline responsiveness and also correlated response with HR status. The strength of our study is the use of neoadjuvant treatment tumor response as the outcome of interest instead of survival over time which has been the outcome measurement in RCT reviews. The weakness of our study is the absence of a sufficient number of TOP2A-amplified patients for a comparison group. It is and would be difficult to obtain a subset of TOP2A-amplified patients for the review of response to neoadjuvant therapy as neoadjuvant patients are more likely to be triple negative with a lower percentage of TOP $2 \mathrm{~A}$ amplification present. To assemble a suitably powerful cohort would require an initial sample size of approximately 200 patients not predominantly triple negative with at least 25\% HER2 positive and 10\% TOP2A-amplified patients $(n=20)$. A sample size of this magnitude would allow for an adequate observational report, but to evaluate the net benefit of TOP2A as a biomarker with the capacity to advise treatment selection an RCT has preferable strength. In lieu of these currently unobtainable options at our institution, we chose to conduct a study with results that can reassure clinicians of the effectiveness of anthracycline therapy previously proven by RCTs and currently called into question by underpowered studies with indirect end points, ie, disease specific and all cause mortality.

Among topoisomerase II normal patients, response was substantial with a $76 \%$ combined complete and PR rate. Both $\mathrm{pCR}$ and overall response rates were highest among HR-negative patients when the 34 cases were compared with HR and HER2 status, though we were unable to compare response with HR-/HER2+ nonresponders due to an absence of patients in that category. Patients who lacked HER-2/neu, PS17, and TOP2A amplification still exhibited a combined $\mathrm{pCR} / \mathrm{PR}$ of $70 \%$ (pCR of $9 \%$ ). By comparison, TOP2A-amplified patients had zero response to neoadjuvant therapy $(\mathrm{n}=3)$ in the study by Kawachi et $\mathrm{al}^{3}$ from a total sample of 14 patients and a pCR of $60 \%(3 / 5)$ was observed in TOP2A-amplified tumors that were estrogen and 
progesterone receptor negative and HER2 positive reported by Orlando et $\mathrm{al}^{5}$ from a total sample size of 23 patients. Both of these studies had fewer patients, $n=14$ and $n=23$, than our current study but had more TOP2A-amplified patients, $\mathrm{n}=3$ and $\mathrm{n}=5$, respectively.

\section{Conclusions}

Initial drug trials in the 1960s using single-agent cyclophosphamide showed a $27 \%$ PR rate in the treatment of metastatic breast cancer. ${ }^{17}$ Complete responses were rare. Although it may be possible that response rates for cyclophosphamide may be slightly higher than the rate of $27 \%$ reported from early trials, it is extremely unlikely that the partial and complete response rates observed in our patient population could be obtained by cyclophosphamide alone. Although a number of studies have suggested that HER2, TOP2A, and/ or PS17 amplification may predict response to DOX, we observed substantial response to treatment in patients lacking all 3 postulated predictors of therapy that would be difficult to attribute to cyclophosphamide alone. Our results indicate HR and HER 2 status are dominant indicators of response in the absence of TOP2A and PS17 amplification. Our results replicate the observations of others that triple-negative breast cancer (HR-/HER2-) patients have a high response rate to anthracyclines. ${ }^{18}$ HER2-negative patients have previously been shown to have a very low incidence of TOP2A amplification or deletion so triple-negative patients likely lack TOP2A amplification or deletion as well. ${ }^{19}$

In general, there is a strong correlation between pCR from neoadjuvant chemotherapy and overall survival, but poor long-term survival has been observed in triple-negative disease despite positive response to initial therapy. ${ }^{18}$ Factors other than those examined here may be involved in the initial response to treatment and those factors may change during the natural history of the disease. Tenari et $\mathrm{al}^{20}$ has reported that TOP2A levels change over time and with treatment. Ejlertsen et $\mathrm{al}^{21}$ has recently reported a correlation between anthracycline responsiveness and tissue inhibitor of matrix metalloproteinases 1(TIMP1), suggesting another molecular target that requires further analysis.

We found a clear utility of anthracycline/cyclophosphamide combined therapy in a cohort of patients treated with neoadjuvant therapy prior to surgery. Future studies may find a link or new marker that will correlate with and/or predict response to anthracycline therapy, but at this time there is insufficient evidence to exclude patients from receiving anthracycline therapy based on HER2, TOP2A, and/or PS17 expression.

\section{Acknowledgment}

This article was supported by the Kaplan Cancer Research Fund.

\section{Disclosure}

The authors report no conflicts of interest.

\section{References}

1. Konecny GE, Pauletti G, Untch M, et al. Association between HER2, TOP2A, and response to anthracycline-based preoperative chemotherapy in high-risk primary breast cancer. Breast Cancer Res Treat. 2010; doi: 10.1007/s10549-010-0744-z.

2. Bartlett JMS, Munro A, Cameron DA, et al. Type 1 receptor tyrosine kinase profiles identify patients with enhanced benefit from anthracyclines in the BR9601 adjuvant breast cancer chemotherapy trial. $J$ Clin Oncol. 2008;26:5027-5035.

3. Kawachi K, Sasaki T, Murakami A, et al. The topoisomerase II alpha gene status in primary breast cancer is a predictive marker of the response to anthracycline-based neoadjuvant chemotherapy. Pathol Res Practice. 2010; doi: 10.1016/j.prp.2009.10.009.

4. Rody A, Karn T, Gatje R, et al. Gene expression profiling of breast cancer patients treated with docetaxel, doxorubicin, and cyclophosphamide within the GEPARTRIO trial: HER-2, but not topoisomerase II alpha and microtubule-associated protein tau, is highly predictive of tumor response. Breast. 2007;16:86-93.

5. Orlando L, Del Curto B, Gandini S, et al. Topoisomerase II $\alpha$ gene status and prediction of pathological complete remission after anthracyclinebased neoadjuvant chemotherapy in endocrine nonresponsive Her2/ neu-positive breast cancer. Breast. 2008;17:506-511.

6. Arpino G, Ciocca DR, Weiss H, et al. Predictive value of apoptosis, proliferation, HER-2, and topoisomerase II $\alpha$ for anthracycline chemotherapy in locally advanced breast cancer. Breast Cancer Res Treat. 2005;92:69-75.

7. Gennari A, Sormani M, Pronzato P, et al. HER2 status and efficacy of adjuvant anthracyclines in early breast cancer: a pooled analysis of randomized trials. J Natl Cancer Inst. 2008;100(1):14-20.

8. Bartlett JMS, Munro AF, Dunn JA, et al. Predictive markers of anthracycline benefit: a prospectively planned analysis of the UK National Epirubicin Adjuvant Trial (NEAT/BR9601). Lancet. 2010; doi: 10.1016/s1470-2045(10)70006-1.

9. Liedtke C, Mazouni C, Hess KR, et al. Response to neoadjuvant therapy and long-term survival in patients with triple-negative breast cancer. J Clin Onc. 2008;25(8):1275-1281.

10. Therasse P, Arbuck SG, Eisenhauer EA, et al. New guidelines to evaluate the response to treatment in solid tumors. $J$ Natl Cancer Inst. 2000;92:205-216.

11. SPSS Version 17.0. Chicago: SPSS, Inc. 2009.

12. Di Leo A, Isola J, Piette F, et al. A meta-analysis of phase III trials evaluating the predictive value of HER2 and topoisomerase II alpha in early breast cancer patients treated with CMF or anthracycline-based adjuvant therapy. San Antonio Breast Cancer Symposium. 2008;705 [abstract].

13. Hanneman J, Kristel P, van Tinteren H, et al. Molecular subtypes of breast cancer and amplification of topoisomerase II $\alpha$ : predictive role in dose intensive adjuvant chemotherapy. British J Cancer. 2006;95: 1334-1341.

14. Rody A, Karn T, Ruckhaberle E, et al. Gene expression of topoisomerase II alpha (TOP2A) by microarray analysis is highly prognostic in estrogen receptor (ER) positive breast cancer. Breast Cancer Res Treat. 2009;113:457-466.

15. Oakman C, Moretti E, Galardi F, et al. The role of topoisomerase II $\alpha$ and HER-2 in predicting sensitivity to anthracyclines in breast cancer patients. Cancer Treat Rev. 2009;35:662-667. 
16. Pritchard KL, Messersmith H, Elavathil L, et al. HER-2 and topoisomerase II as predictors of response to chemotherapy. J Clin Oncol. 2008;26:736-744.

17. Devita VT, Young RC, Canellos GP. Combination versus single agent chemotherapy: a review of the basis for selection of drug treatment for cancer. Cancer. 1975;35:98-110.

18. Carey LA, Dees EC, Sawyer L, et al. The triple negative paradox: Primary Tumor Chemosensitivity of Breast Cancer Subtypes. Clin Cancer Res. 2007;13:2329-2334.

19. Jarvinen TA, Tanner M, Rantanen V, et al. Amplification and deletion of topoisomerase IIalpha associate with ErbB-2 amplification and affect sensitivity to topoisomerase II inhibitor doxorubicin in breast cancer. Am J Pathol. 2000;156:839-847.
20. Tenari N, Lattanzio R, Natoli C, et al. Changes in topoisomerase II $\alpha$ expression in breast tumors after neoadjuvant chemotherapy predicts relapse-free survival. Clin Cancer Res. 2006;12(5):1501-1506.

21. Ejlertsen B, Maj-Britt J, Nielsen KV, et al. HER2, TOP2A, and TIMP-1 and responsiveness to adjuvant anthracycline-containing chemotherapy in high-risk breast cancer patients. J Clin Oncol. 2010;28:984-990.

\section{Publish your work in this journal}

Cancer Management and Research is an international, peer-reviewed open access journal focusing on cancer research and the optimal use of preventative and integrated treatment interventions to achieve improved outcomes, enhanced survival and quality of life for the cancer patient. The journal welcomes original research, clinical \& epidemiological studies, reviews \& evaluations, guidelines, expert opinion \& commentary, case reports \& extended reports. The manuscript management system is completely online and includes a very quick and fair peerreview system, which is all easy to use. Visit http://www.dovepress.com/ testimonials.php to read real quotes from published authors. 